\title{
CRÓNICA Y ACTITUD DE UN CONSTITUCIONALISTA. LA TESIS DE ADOLFO POSADA SOBRE LA TITULARIDAD DE LA SOBERANÍA
}

\author{
Remedios Morán Martín
}

doi: 10.18543/ed-64(1)-2016pp361-375

\begin{abstract}
Sumario: 1. ObJetivo. 2. El tema de la titularidAd DE LA SOBERANÍA en Adolfo Posada. 2.1. Contexto intelectual. 2.2. Sentido de la titularidad de la soberanía en las Constituciones españolas. 3. VIVENCIA DE LA TITULARIDAD DE LA SOBERANÍA EN EL CONSTITUCIONALISMO ESPAÑOL. 4. LA APLICACIÓN DE LA TEORÍA CONSTITUCIONAL DE AdOLFo PosAdA A LA FÓRMULA DE LA CONSTITUCIÓN DE 1978.
\end{abstract}

\section{OBJETIVO}

Oriento las observaciones recogidas en estas páginas a señalar cual fue la preocupación principal que puede deducirse de los escritos de Adolfo Posada acerca de la forma política que la historia constitucional había impuesto a la España de su tiempo. Intentaré también mostrar cómo, pese a su evidente fracaso real, el peso de su lógica interna fue tal, que los constitucionalistas de 1978 optaron por sortear su tesis, casi al modo en que se «ocultan» algunos de los intérpretes del Derecho musulmán.

No puede ser entendido Adolfo Posada (Adolfo González-Posada y Biesca) como un constitucionalista stricto sensu. El conjunto de su obra lo presenta

* Este trabajo se ha realizado dentro del Proyecto de investigación I + D + I, Participación y exclusión política (causas, mecanismos, consecuencias), DER2013-46338-R. 
como un pensador especialmente centrado en la visión del mundo generada por la recepción y evolución del krausismo en España ${ }^{1}$. Esa actitud le impuso asumir un papel muy activo como reformador social ${ }^{2}$. Sustentado por una raíz pedagógica $^{3}$, que buscaba conocer y aplicar cuantas herramientas intelectuales, especialmente el Derecho y la Sociología ${ }^{4}$, le permitieran diagnosticar la reali-

${ }^{1}$ El mismo Posada escribe una Breve historia del krausismo español, Universidad de Oviedo, 1981. Asimismo, todos los estudios sobre el krausismo lo insertan en esta corriente que, para Posada, se reelaboró en España y tuvo como fin la regeneración ética en todos los aspectos: PosadA, A., España en crisis (La política), Ed. Caro Raggio, Madrid, 1923, especialmente pp. 173-174. Entre otros estudios sobre el tema, vid., ENRIQUE M. UREÑA y Álvarez LÁZARo, P. (eds.), La actualidad del krausismo en su contexto europeo, Editorial Parteluz, Madrid 1999, así como los numerosos trabajos publicados por el grupo de investigación fundado por estos dos autores en la Universidad de Comillas con el nombre de Liberalismo, krausismo y masonería, dirigido actualmente por J. M. Vázquez Romero: <http://dialnet.unirioja.es/servlet/listalibrosporcoleccion?codigo=193>; Laporta, F., Adolfo Posada: Política y sociología en la crisis del liberalismo español, Cuadernos para el diálogo, Madrid, 1974, para este tema, especialmente pp. 257-313, que, al situarse en la óptica de la Filosofía del Derecho, es el estudio que mejor señala la perspectiva general desde la que debe ser valorado Posada; DíAz, E., La filosofía social del krausismo español, Cuadernos para el diálogo, Madrid, 1973, pp. 49-52, 74-75, passim. Asimismo, PÉREZ-PREndes, J. M., «Las ciencias jurídicas», en Historia de España, fundada por Ramón Menéndez Pidal, dirigida por José María Jover Zamora, Tomo XXXIX.2, La Edad de plata de la cultura española (1898-1936), Espasa-Calpe, Madrid, 1994, pp. 341-388, donde el autor expone un cuadro de la ciencia jurídica del krausismo.

${ }^{2}$ Le Droit et la question sociale, M. Giard \& E. Brière, Paris, 1898; El Derecho y la cuestión social, Estudio preliminar a Menguer, El Derecho civil y los pobres, Librería de Victoriano Suárez, Madrid, 1898; Socialismo y reforma social, Est. Tipográfico de Ricardo Fé, Madrid, 1904, etc. además de las cuestiones relacionadas con la mujer, cuya síntesis recogió en su obra Feminismo, Librería de Fernando Fé, Madrid, 1899. Sobre sus propuestas de reforma, vid., Monereo PÉrez, J. L., La reforma social en España: Adolfo Posada, Ministerio de trabajo y Asuntos sociales, Madrid, 2003.

${ }_{3}$ Entre sus estudios sobre el tema, destacan: La enseñanza del Derecho en las Universidades. Estado actual de la misma en España y proyectos de reformas, Imprenta de la Revista de las Provincias, Oviedo, 1889; Política y enseñanza: Política pedagógica. La reforma de la primera enseñanza. La segunda enseñanza, Daniel Jorro, Madrid, 1904; Pedagogía, Ed. Sempere, Valencia, 1909. Vid., Terrón, E., Sociedad e ideología en los orígenes de la España contemporánea, Ediciones Península, Barcelona, 1969.

${ }_{4}$ Principios de sociología, Ginés Carrión, Madrid, 1908; Socialismo y reforma social, Madrid, 1904; Builla, A.; Posada, A. y Morote, L., El instituto de trabajo. Datos para la historia de la reforma social en España, Con un discurso preliminar de José Canalejas y Méndez y una Memoria acerca de los Institutos del Trabajo en el extranjero por J. Uña y Sarthou, Establecimiento tipográfico de Ricardo Fré, Madrid, 1904 (reed. Ministerio de Trabajo y Seguridad Social, Madrid, 1966 y 1986). Vid., Olaza Pallero, S., «La influencia de la legislación y la doctrina española en el Proyecto de Ley Nacional del Trabajo de Joaquín V. González», en Revista de Historia del Derecho, 36, 2008, pp. 229-255: <dialnet.unirioja.es/descarga/articulo/4631203.pdf > [consulta: 3-12-2015]. 
dad socio-política española e hispanoamericana $;$ y procuró situarla en un contexto internacional ${ }^{6}$, estableciendo aquellas modificaciones que juzgaba necesarias para alcanzar el modelo de vida colectivo que entendía como más noble ${ }^{7}$.

\section{EL TEMA DE LA TITULARIDAD DE LA SOBERANÍA EN ADOLFO POSADA}

\subsection{Contexto intelectual}

Considerado monográficamente, está claro que Adolfo Posada eligió tratar el asunto en la sede apropiada, el Derecho político ${ }^{8}$, que además le era

${ }^{5}$ Entre su amplia obra sobre el tema destaco: Estudios sobre el régimen parlamentario en España, Biblioteca Económica y Filosófica, Vol. 57, Madrid, 1891 (hay edición con «Estudio preliminar» de F. Rubio Llorente, Clásicos Asturianos del Pensamiento Político, Oviedo, 1996); Tratado de Derecho político, Librería General de Victoriano Suárez, Madrid, 1893-1894, 2 vols.; Guía para el estudio y aplicación del Derecho constitucional de Europa y América, Librería de Victoriano Suárez, Madrid, 1894; Instituciones políticas de los pueblos hispano-americanos, Imprenta de la Revista de Legislación, Madrid, 1900; Derecho politico comparado. Capitulos de introducción, Librería General de Victoriano Suárez, Madrid, 1906; Para América desde España, Sociedad de Ediciones Literarias y Artísticas, París, 1910; La República del Paraguay. Impresiones y comentarios, Librería General de Victoriano Suárez, Madrid, 1911; La República Argentina, Librería General de Victoriano Suárez, Madrid, 1912; La crisis del Estado y el Derecho político, C. Bermejo Impresor, Madrid, 1934, etc. Sobre el tema en Posada, vid., SorIA Moya, M., Adolfo Posada, teoría y práctica política en la España del siglo XIX (recurso electrónico), València, Universitat de València, Servei de Publicacions, 2004. 1 disco (CD-ROM). <http://www.tdx.cat/bitstream/handle/10803/9681/soria.pdf;jsessionid=363 BAA9810529FA0D3AD559DAA70290D.tdx1? sequence=1 $>$ [consulta: 4-1-2016].

${ }^{6}$ Siempre dedicó amplios capítulos de su obra al Derecho comparado, como puede apreciarse en las obras citadas en la nota anterior, muy significativamente en su Tratado de Derecho político. Además, realizó varios estudios preliminares a las obras más interesantes del pensamiento europeo, entre ellas: Estudio preliminar sobre las ideas jurídicas y el método realista de Ihering. R. Ihering, Prehistoria de los indoeuropeos, Librería General de Victoriano Suárez, Madrid, 1896; Estudio preliminar a G. Jellinek, La declaración de los Derechos del hombre y del ciudadano, Librería General de Victoriano Suárez, Madrid, 1908; Estudio preliminar a León Duguit, Las transformaciones del Derecho público, Francisco Beltrán, Librería española y extranjera, Madrid, 1915; etc. además de obras específicas en las que analizaba la política internacional de su momento, como La idea del Estado y la guerra europea, Librería General de Victoriano Suárez, Madrid, 1915; Actitud ética ante la guerra y la paz, Caro Raggio, Ed., Madrid, 1923; La Sociedad de Naciones y el Derecho político, Caro Raggio, Ed., Madrid, 1925, etc.

7 Sobre sus propuestas de reforma, vid., Monereo PÉrEz, J. L., La reforma social en España: Adolfo Posada, Ministerio de trabajo y Asuntos sociales, Madrid, 2003.

8 Tratado de Derecho político, Librería General de Victoriano Suárez, Madrid, 18931894, 2 vols. (del cual se publicaron cinco ediciones revisadas, la última de 1935, que es la que utilizo en este trabajo, salvo cita expresa de otra edición). 
profundamente familiar, al ser un núcleo de sus conocimientos, aunque no el único, como ya he señalado en las notas anteriores.

Dicha idea aparece en su pensamiento dentro de varios círculos concéntricos: uno, el dedicado a la doctrina de soberanía en general ${ }^{9}$ y otro, a las formas históricas constitucionalizadas del Estado en España ${ }^{10}$. En este segundo círculo, a partir de una primera etapa (1812-1833) expone su examen, sin duda el mejor publicado hasta ese momento, que se cierra con el estudio de la entonces novísima y vigente Constitución de 1931. Ese marco se construyó en continua evolución a medida que iba presentándosele la necesidad de estudiar y valorar la sucesión de movimientos políticos en España. Siendo «bruscas» las causas que llevan a los cambios políticos y constitucionales del siglo XIX, no lo son las reflexiones de Posada sobre ellas, sino que en una secuencia continuada de obras va perfilando tenazmente su pensamiento. En la aparentemente breve exposición de los párrafos en que trata la Historia del Derecho constitucional en España, Adolfo Posada, no da pinceladas, como pueda parecer, sino que cincela como si de piedra se tratara, cada una de las ideas que expone, en sí mismas merecedoras de un análisis extenso. Asimismo, parte de estas páginas son resumen excelente de una exposición más amplia que publicó en gran medida como crítica sobre parte del articulado de la Constitución de 1931, que expuso en su obra La Nouvelle constitution espagnole $^{11}$.

Para Posada, la comprensión de efecto determinador de la titularidad de la soberanía en los Estados constitucionales, exige varias interpretaciones de carácter general y de significación tanto jurídica y política, unas veces en abstracto y otras impuestas por la naturaleza especial, histórica, del régimen constitucional en sus diferentes tipos.

9 Ibid., libro VI, capítulos I y II, libro sexto, del vol. primero, pp. 313-427.

${ }^{10}$ Ibid., libro II, capítulo VI y VII del vol. segundo, pp. 258-328 y libro III, cap. V. pp. 360-363 (desde ahora cito solo vol. y pp.). Aunque el desarrollo de la Soberanía está recogida en el resto de las ediciones, en la quinta edición introduce el capítulo VII dedicado a la Constitución de 1931, que obviamente no se recoge en la edición cuarta, de 1928. El libro III de este volumen en sus diferentes ediciones lo dedica a un estudio de Derecho comparado de la soberanía en diferentes constituciones europeas.

11 PosadA, A., La Nouvelle constitution espagnole. Le régime constitutionell en Espagne. Evolution. Textes. Commentaires, Librairie du Recueil Sirey, Paris, 1932. Esta obra tuvo una amplia repercusión en Francia, no solo por ser publicada en París, sino por la recensión que le hizo SARRAIL, J., en Bulletin Hispanique, vol. 35. 2, pp. 198-199: $<$ http://www.persee.fr/web/revues/home/prescript/article/hispa_0007-4640_1933 num_35_2_2581_t1_0198_0000_2>. Recientemente ha sido publicada con traducción del texto por Antonio María BuENo ARMIJO y Estudio preliminar a cargo de Joaquín VARela Suanzes-Carpegna, Instituto Nacional de Administraciones Públicas, Madrid, 2006, 2 vols. Cito por esta edición, vol. II que corresponde a la traducción española. 
Respecto a las interpretaciones jurídicas y políticas, lo esencial es saber claramente en quién y dónde reside el poder generador del Estado y su régimen, estableciendo por quién y cómo se ejerce dicho poder, al diferenciarse en funciones. Cuando en la Constitución no se menciona expresamente la determinación del titular de la soberanía, aquélla puede realizarse bien mediante la interpretación del Preámbulo, bien en el procedimiento de reforma constitucional, porque es en ellos donde se señalan los órganos a quienes se atribuye el Poder para realizar el acto específico por excelencia de soberanía; a falta de ambos, debe atenerse al funcionamiento práctico del régimen institucional ${ }^{12}$.

Pasando ahora a la aplicación de ese método a la Historia del constitucionalismo español, resulta que primero entre 1812 y 1834, se plantea la lucha entre el absolutismo y el constitucionalismo, concretándose en dos soluciones: los que consideraban que la titularidad de la soberanía residía en un ente identificado como «soberanía nacional» y los que la atribuían a la Corona y a las Cortes, que optaban por una interpretación de la historia. En ese quién y dónde reside la titularidad del ente soberano, Posada considera que se recoge una fórmula jurídico política dogmática de la soberanía nacional en el art. 3 de la Constitución de Cádiz ${ }^{13}$, en el preámbulo de Constitución de $1837^{14}$, y las Constituciones de 1856 (la non nata) ${ }^{15}$, de $1869^{16}$, todas ellas obra de

12 PosadA, A., Tratado de Derecho político, II, pp. 329-333.

13 «La soberanía reside esencialmente en la Nación, y por lo mismo pertenece a ésta exclusivamente el derecho de establecer sus leyes fundamentales». El mecanismo de reforma en el título X, arts. 372-384.

${ }^{14}$ Doña Isabel II, por la gracia de Dios y la Constitución de la Monarquía Española, Reina de las Españas, y en su Real nombre, y durante su menor edad, la Reina Viuda su Madre Doña María Cristina de Borbón, Gobernador del Reino; a todos los que las presentes vieren y entendieren, sabed: Que las Cortes generales han decretado y sancionado, y Nos de conformidad aceptado, lo siguiente: Siendo la voluntad de la Nación revisar, en uso de su soberanía, la Constitución política promulgada en Cádiz el 19 de Marzo de 1812 , las Cortes generales, congregadas a este fin, decretan y sancionan la siguiente Constitución de la Monarquía Española».

15 Art. 1: «Todos los poderes públicos emanan de la Nación, en la que reside esencialmente la soberanía, y por lo mismo pertenece exclusivamente a la Nación el derecho de establecer sus leyes fundamentales». La reforma constitucional en el título XV.

16 Preámbulo: La Nación española, y en su nombre las Cortes Constituyentes elegidas por sufragio universal, deseando afianzar la justicia, la libertad y la seguridad, y proveer al bien de cuantos vivan en España, decretan y sancionan la siguiente Constitución»; art. 32: «La soberanía reside esencialmente en la Nación, de la cual emanan todos los poderes». La reforma constitucional en el título XI, arts. 110-112: Art. 110. «Las Cortes, por sí o a propuesta del Rey, podrán acordar la reforma de la Constitución, señalando al efecto el artículo o artículos que hayan de alterarse». 
Cortes constituyentes. Por el contrario, las de $1845^{17}$ y 1876 (la Constitución de Cánovas $)^{18}$, elaboradas por las Cortes con el rey, no mencionan el tema de la titularidad de la soberanía, como tampoco lo hicieron el Estatuto de Bayona de 1808, ni el Estatuto Real de 1834. Por lo tanto estos dos textos asumieron una suerte de pacto entre el Rey y su pueblo, que se tradujo en el texto constitucional presentándolo como fruto de la coincidencia entre voluntad regia y la de las Cortes. Finalmente, la Constitución de $1931^{19}$ reanuda el proceso de adaptación del principio dinámico de la soberanía nacional a que respondían las Constituciones de 1812, 1837 y 1869, donde el principio activo de la soberanía era la Nación.

\subsection{Sentido de la titularidad de la soberanía en las Constituciones españolas}

Sin ser exhaustiva en el análisis de la obra de Posada, es constante su progresiva elaboración de su doctrina en torno a la evolución ideológica del Estado, hasta llegar al punto esencial de la soberanía y su titularidad. Desde la primera edición de sus dos volúmenes del Tratado de Derecho Político (18931894), cuando entró como catedrático en la Universidad de Oviedo, elaboró para dicho curso y siguientes un tercer tomo, la Guía para el estudio y aplicación del Derecho constitucional de Europa y América ${ }^{20}$. Pues bien, tanto en el tomo I del Tratado como en la Guía, se aprecia esa gestación del tema que nos

17 «Doña Isabel II, por la gracia de Dios y la Constitución de la Monarquía Española, Reina de las Españas; a todos los que las presentes vieren y entendieren, sabed: Que siendo nuestra voluntad y la de las Cortes del Reino regularizar y poner en consonancia con las necesidades actuales del Estado los antiguos fueron y libertades de estos Reinos, y la intervención que sus Cortes han tenido en todos tiempos en los negocios graves de la Monarquía, modificando al efecto la Constitución promulgada en 18 de Junio de 1837, hemos venido, en unión y de acuerdo con las Cortes actualmente reunidas, en decretar y sancionar la siguiente Constitución de la Monarquía española».

18 «Don Alfonso XII, por la gracia de Dios Rey constitucional de España. A todos los que las presentes vieren y entendieren, sabed: que en unión y de cuerdo con las Cortes del Reino actualmente reunidas, hemos venido en decretar y sancionar la siguiente Constitución de la Monarquía española».

19 Preámbulo: «España, en uso de su soberanía, y representada por las Cortes constituyentes, decreta y sanciona esta constitución». Art. 1. «España es una República democrática de trabajadores de toda clase, que se organiza en régimen de Libertad y de Justicia. Los poderes de todos sus órganos emanan del pueblo». Art. 51. La potestad legislativa reside en el pueblo, que la ejerce por medio de las Cortes o Congreso de los Diputados»». Vid. Posada, A., Tratado de Derecho político, pp. 362-363.

${ }^{20}$ Id., Guía para el estudio y aplicación del Derecho político, Librería de Victoriano Suárez, Madrid, 1894. Esta Guía no se volvió a publicar, siguiendo las siguientes ediciones solo los tomos I y II. 
interesa. Me centro en sus palabras iniciales en la Guía porque al ser unas frases para el estudio del Derecho político, dedicadas a estudiantes fundamentalmente, expone de forma clara la base en la que se fundamenta:

«No siempre es dable inferir de las Constituciones escritas, sea atendiendo á su texto, sea interpretando su tenor general, el principio de la soberanía imperante de un modo real y efectivo ó práctico en el Estado. Por un lado, hay constituciones escritas que no sólo no contienen declaración alguna solemne acerca del soberano, sino que les falta hasta la indicación respecto de la reforma constitucional, indicación ésta que tanto puede servir para inferir quién se reputa en el Estado depositario del poder supremo. Por otra parte, aunque ciertas Constituciones contengan, ó la declaración solemne, o el procedimiento de reforma de la Constitución, puede ocurrir que real y positivamente el principio de la soberanía imperante sea distinto de lo que en pura teoría significan la declaración y el procedimiento aludidos. En estos dos casos, el problema de la soberanía tiene que resolverse mediante el estudio de las condiciones históricas en que el Estado viva, induciendo el principio dominante de los hechos mismos en que puede manifestarse $»^{21}$.

A partir de aquí, ya poniendo en relación la Guía con la materia desarrollada en el Tratado, diferencia entre las Constituciones que contienen declaración expresa acerca de la soberanía o del poder supremo del Estado, y dentro de éstas las que atribuyen la misma en la nación o pueblo y las que lo atribuyen el poder supremo al rey (otras tienen una soberanía mixta: rey y pueblo, como la portuguesa vigente en su momento, o la española de Cánovas), como se ha dicho más arriba; incluso hay constituciones que contienen disposiciones de las que pueden inferirse su doctrina acerca de la soberanía, frente a otras que no las contienen (como la española de Cánovas). Finalmente, Posada relaciona también con este tema las Constituciones que contienen disposiciones relativas al procedimiento para la revisión o reforma constitucional. Me centraré en estas dos que son las que más me interesan entre las que analiza Posada, para la exposición que aquí pretendo, la de 1876 y la de 1931, para después intentar conectar sus consecuencias en la Constitución de 1978. Por lo tanto, a tenor del razonamiento de Posada, lo fundamental del régimen político constitucional, en este punto, es atenerse con sumo cuidado y exactitud a la técnica constitucional previamente fijada, acerca de la cual no caben interpretaciones alejadas de las propiamente literales.

Considera Posada que la primera etapa del constitucionalismo, 18121833, denominada por él «de intentos y ensayos de constitucionalización del Estado en España», se caracteriza en general por el enfrentamiento entre los partidarios del Antiguo régimen y del nuevo, para oponerse después:

${ }^{21}$ Ibid., p. 141. Las cursivas son del propio texto. 
«Dos soluciones 'constitucionales', a menudo de un constitucionalismo muy atenuado, soluciones que se concretan en afirmaciones y rectificaciones de significación diversa, las cuales se producen con interrupciones bruscas en el correr de la historia, y las cuales separan períodos de más o menos duración, encerrados entre acontecimientos violentos» ${ }^{22}$.

Conviene exponer aquí, siquiera sea en síntesis, el sentido que otorga Posada a esas «interrupciones bruscas», en el punto de la titularidad de la soberanía, subrayando que a consecuencia de ello, quedará condicionado el régimen político que se adopte en la Constitución correspondiente, según el sentido último del pensamiento de Adolfo Posada y la conexión que en dicha teoría realizaran sus discípulos, de modo especial Nicolás Pérez Serrano, uno de sus más próximos y continuador en su cátedra.

Sostiene Posada que los movimientos que se desarrollan en España tendentes a la creación del nuevo régimen republicano que cierra en su tiempo la historia constitucional de nuestro país no tienen «precedentes tradicionales» en España, sino que la influencia procede de Francia, puesto que entre nosotros la única tradición existente era la Monarquía, que era una titular de la soberanía y la ejercía absolutamente.

«Faltaba, pues, un verdadero enlace histórico entre el proceso tradicional del absolutismo y la formación del régimen constitucional que se introducirá, sobre todo, merced a una sugestión ideológica, y a las circunstancias favorables que ofrecía la evidente desorientación nacional entonces existente $\rangle^{23}$.

Aunque parece seguir manteniendo la teoría de Martínez Marina sobre la restauración de las Cortes históricas castellano-leonesas con la Constitución de 1812 y la ruptura institucional de los Borbones respecto a las mismas ${ }^{24}$, no obstante, en el desarrollo de su teoría va más allá de tal criterio, al considerar, como se refleja en sus palabras citadas, que no había precedente en España, de tal manera que a pesar de la apariencia del Discurso preliminar de dicha Constitución, su articulado excede del mismo con la construcción de un nuevo Estado, especialmente cuando, tras una larga trayectoria histórica de monarquía absoluta, puede relacionarse en gran medida con los principios de la Constitución francesa de 1791, especialmente cuando, en el tema que me ocupa en esta exposición, establece el principio de soberanía nacional

22 Id., Tratado de Derecho Politico, II, p. 259.

${ }^{23}$ Ibid., II, p. 264.

${ }^{24}$ Ibid., II, pp. 265-266, 271 y ss., y La nueva constitución, II, pp. 11 y ss. Sobre la naturaleza jurídica de las Cortes histórica, vid., PÉrEz-Prendes, José Manuel, Cortes de Castilla, Ed. Ariel, Barcelona, 1974 (hay una segunda ed. a cargo de MorÁn MARTín, R.: Pérez-Prendes, J. M., Cortes de Castilla, reimpresión y nuevos estudios, Servicio de Publicaciones de la UCM, Facultad de Derecho, Madrid, 2000). 
(Preámbulo, arts. 2, 3, 14, etc.) y además explícitamente se recoge en el art. 2. ${ }^{\circ}$ que: «La nación española es libre e independiente, y no es, ni puede ser, patrimonio de ninguna familia ni persona $\rangle^{25}$.

Asimismo, admite también que la Constitución de Cádiz se separa sustancialmente de la tradición al organizar las Cortes, que no se convocan por brazos o estamentos, sino que dicta que las Cortes: «son la reunión de todos los diputados que representan a la nación, nombrados por los ciudadanos» (art. 27). También está admitiendo conscientemente que no es «tradicional» la Constitución de Cádiz, cuando insiste con claridad en que a la vuelta de Fernando VII anula toda la labor realizada en Cádiz. Pero en todo caso, lo que entiendo como más sustantivo de su pensamiento en estas consideraciones, es que Posada considere:

«Lo esencial para el régimen político de Constituciones (...) [es] que sus instrumentos y métodos respondan a las que se vienen estimando como exigencias capitales de un régimen jurídico de Estado, tal y como este régimen se haya llegado a sentir y a formular por el respectivo pueblo -soberano-. Esto, por otra parte explica la variedad de formas constitucionales eficaces, cada una a su modo, así como la diversidad de procedimientos de garantía del propio instrumento constitucional, y que en cierto respecto se ofrecen, por ejemplo en fórmulas extremas (...) de lo que puede llamarse la técnica constitucional, o sea la técnica para la realización práctica del régimen, fórmulas que suponen -o piden- el antecedente inspirador o la justificación de una idea y de un ideal de Derecho como función y fin: esencia del Estado» ${ }^{26}$.

\section{VIVENCIA DE LA TITULARIDAD DE LA SOBERANÍA EN EL CONSTITUCIONALISMO ESPAÑOL}

Prescinde Posada del proceso que se siguió en las Cortes de 1789, presididas y orquestadas por Campomanes, que ha sido objeto de estudios posteriore ${ }^{27}$ y contempla el panorama que se abre tras la muerte de Fernando VII en 1833. La lucha entre los partidarios de la hija de Fernando VII, Isabel y el

${ }^{25}$ PosADA, A., Tratado de Derecho politico, II, p. 278. «En rigor, los legisladores de Cádiz, que podían legítimamente recordar el valor histórico y constitucional de las viejas tradiciones políticas españolas, establecieron un régimen nuevo, menos bajo la influencia de su erudición de historiadores que de la ideología triunfante de la Revolución, como intentaré demostrar a continuación», Id., La nueva constitución, II, pp. 15 y ss.

${ }^{26}$ Id., El régimen constitucional. Esencia y forma. Principios y técnica, Librería General de Victoriano Suárez, Madrid, 1930, pp. 20-21.

${ }_{27}$ Sobre el debate en torno la monarquía y la sucesión a la Corona que se desarrolla en las últimas Cortes de los Borbones del Antiguo Régimen, vid., PÉrEz-Prendes, José Manuel, «1789. Las Cortes de los Borbones», en Fuentes Ganzo, E. (ed.), De las Cortes 
hermano de aquél, el infante D. Carlos, terminó con la victoria de Isabel, fundamentándose su derecho en la puesta en vigor por Fernando VII, mediante pragmática de 1830 de la ley de Cortes de Carlos IV de 1789, del orden de sucesión castellano de las Partidas (2.15.2) y que provoca la derogación de la llamada ley Sálica, en su interpretación francesa debida a Jean Bodin, por la que excluía a las hembras de la sucesión al trono (introducida en España por Felipe V mediante auto acordado de 1713). Para Posada, lo que se denominó en su momento «la cuestión dinástica», y que no era otra cosa en el fondo que la atribución de la titularidad de la soberanía, que modifica la marcha del proceso constitucional, porque no solo se trataba de un pleito sucesorio, sino de un problema político, porque se trataba de dilucidar el régimen propio de la España moderna: la lucha entre los partidarios de la soberanía nacional y los partidarios de la soberanía del rey ${ }^{28}$. Por este motivo, a la muerte de Fernando VII los partidarios del régimen absolutista se afiliaron a la causa de Carlos y los del régimen constitucional a la de Isabel.

Lo que caracteriza para el profesor ovetense la época que corre desde 1833 a 1875 , son las agitaciones y saltos bruscos. Pero sin embargo para Posada se mantiene una «legalidad monárquica», entre 1837 y 1868, dentro de la cual luchan diversas soluciones constitucionales, no ya, como en el anterior periodo, entre el antiguo y el nuevo régimen; de hecho, incluso con el régimen del 68 y se mantiene la legalidad constitucional de la monarquía como forma de gobierno por «disposición constitucional», que se rompe con la abdicación de Amadeo de Saboya y la llegada de la I República y su proyecto de constitución federal de 1873 que no pasó de esto por el golpe de Estado del general Pavía (3 de enero de 1874) y la dictadura.

Un nuevo y brusco cambio, el alzamiento del general Martínez Campos en Sagunto, en 1874, propició la Restauración y la restauración de la monarquía, en Alfonso XII, presentada como un «continuar la historia de España», mediante la «Monarquía hereditaria y constitucional».

Para Posada, «La idea de Monarquía hereditaria -nacional-y constitucional -moderada por las Cortes, institución nacional-, la sostuvo siempre el inspirador civil de la Restauración, Cánovas del Castillo. La Monarquía y las Cortes eran para el autor (...) de la Constitución de 1876 la esencia de la historia política de España ${ }^{29}$, por lo que retomaba el doctrinarismo propio de los principios de nuestro constitucionalismo, cuyas fórmulas del rey con las Cortes contrastan con las utilizadas en Constituciones como las del 12, 37 y 69, que en sus preámbulos sólo hablan de las Cortes como depositarias de la

históricas a los Parlamentos democráticos. Castilla y León. S. XII-XXI, Benavente, 2003, pp. 313-332.

${ }_{28}$ Posada, A., Tratado de Derecho Político, II, pp. 282 y ss.

${ }^{29}$ Ibid., II, p. 297. 
soberanía nacional. En esta situación la Constitución canovista de 1876, para Posada tiene tres periodos:

1. La Restauración propiamente dicha: desde 1876 hasta la muerte de Alfonso XII (25-XI-1886)

2. Regencia de María Cristina: desde esta fecha al 17 de marzo de 1902 (mayoría de edad de Alfonso XIII).

3. El reinado de Alfonso XIII hasta el 13 de septiembre de 1923, fecha en que por los sucesos de Barcelona quedó en suspenso, sin efectos jurídicos la Constitución (real decreto de 15 de sept. De 1923).

Durante este periodo, 1876-1923, la Constitución es la misma, pero no su práctica, en todo caso pone fin en septiembre de 1923 con una violenta rectificación del proceso constitucional mediante el entronizamiento, con apoyo real, de una dictadura ${ }^{30}$. Para Posada, en resumen, la clave está en el uso que hace Alfonso XIII del art. 32 de la Constitución, disolviendo las Cortes por decreto de 15 de septiembre de $1923^{31}$ y el mismo día por otro decreto, para Posada claramente inconstitucional, que dispone:

«El presidente del Directorio militar» sea el «encargado de la gobernación del Estado, con poderes, dice el Rey, para proponerme cuantos decretos convengan a la salud pública, los que tendrán fuerza de ley ínterin en su día no sean modificados por leyes aprobadas por las Cortes del reino y sometidas a mi Real sanción $)^{32}$.

Los presidentes del Senado (Conde de Romanones) y del Congreso (Melquiades Álvarez) recordaron sin éxito al rey el art. 32 de la Constitución de Cánovas:

«Las Cortes se reúnen todos los años. Corresponde al Rey convocarlas, suspender, cerrar sus sesiones y disolver simultánea o separadamente la parte electiva del Senado y el Congreso de los Diputados, con la obligación, en este caso, de convocar y reunir el Cuerpo o Cuerpos disueltos dentro de tres meses».

Y Alfonso XIII, el día 13 de noviembre de 1923 cesa en sus funciones a ambos y no convoca las elecciones en los tres meses que fija dicho art. de la Constitución.

Para Adolfo Posada este es el momento de destrucción del régimen constitucional, precisamente por la mutación que acarrea en el tema de la atribu-

${ }^{30}$ La base documental en la que se basa Posada, puede seguirse en ibid., pp. 300-303 y La nueva constitución, II, pp. 75-79.

31 Dos días antes por otro decreto había suspendido las garantías constitucionales.

32 Posada, A., Tratado de Derecho Político, II, p. 301. 
ción de la titularidad de la soberanía. Es imprescindible seguir los pasos, como el mismo Posada resume, de su tesis:

«Como consecuencia de la renuncia de éste [Amadeo de Saboya] proclamaron las Cortes la República -la primera República- en 1873, que no logró consolidarse. Un movimiento militar - un pronunciamiento- realizó la restauración borbónica (1874-75), entrando a reinar Alfonso XII y elaborándose en Cortes la Constitución de 1876, vigente hasta que, roto por el Rey el pacto constitucional en 1923, quedó aquélla en suspenso, no siendo posible reanudar su vigencia en 1930 -al caer la dictadura-, y realizándose en 1931 un fuerte movimiento de opinión que provocó la proclamación de la segunda República (abril 1931), que ordena su legalidad con la Constitución de 9 de noviembre de 1931, que es la vigente» ${ }^{33}$.

Por lo tanto, la tesis de Posada afirma que, al violar Alfonso XIII el pacto constitucional que daba todo fundamento en la Constitución de Cánovas, mediante la distribución de la titularidad de la soberanía entre el monarca y el pueblo representado en Cortes generales de Congreso y Senado, no era ya posible reanudar la normal aplicación del régimen constitucional que había quedado destruido por el incumplimiento del art. 32 de la Constitución canovista, en su momento vigente. La parte cotitular de la soberanía, ahora única, el pueblo soberano, manifestó en las elecciones municipales de abril de 1931 su voluntad de adoptar una forma política distinta a la derribada y dio con ello lugar a la proclamación de la II República ${ }^{34}$.

\section{LA APLICACIÓN DE LA TEORÍA CONSTITUCIONAL DE ADOLFO POSADA A LA FÓRMULA DE LA CONSTITUCIÓN DE 1978}

El 14 de mayo de 1977, en un discurso dado en el palacio de la Zarzuela, D. Juan de Borbón, hizo renuncia oficial de sus derechos en favor de su hijo, el rey Juan Carlos I, reservándose para sí el uso del título de conde de Barcelona, inherente a los soberanos españoles. Esto llevó a que se redactaran del siguiente modo tanto el preámbulo de la Constitución de 1978 y los artículos 1.2 y 57.1 :

«Preámbulo: D. Juan Carlos, rey de España, a todos los que la presente vieren y entendieren. Sabed: que las Cortes han aprobado y el pueblo español ratificado la presente Constitución. (...)

${ }^{33}$ Ibid., II, p. 260. Ampliamente trata este tema en La nueva constitución, II, pp. $80-88$.

${ }^{34}$ Este tema fue expuesto por Pérez-Prendes, J. M., «Significado de la II República», en Fundación Institucional Española, La Monarquía española entre las constituciones de 1876 y 1978, Centro de Estudios políticos y Constitucionales, Madrid, 1999, pp. 199-215. 
Art. 1.2. La soberanía nacional reside en el pueblo español, del que emanan todos los poderes del Estado.

Art. 57.1. La Corona de España es hereditaria en los sucesores de S. M. Don Juan Carlos I de Borbón, legítimo heredero de la dinastía histórica. La sucesión en el trono seguirá el orden regular de primogenitura y representación, siendo preferida siempre la línea anterior a las posteriores; en la misma línea, el grado más próximo al más remoto; en el mismo grado, el varón a la mujer, y en el mismo sexo, la persona de más edad a la de menos ${ }^{35}$.

¿Existe alguna coherencia entre las opiniones de Adolfo Posada y los hechos y textos constitucionales del 1931, que deposita la soberanía en la Nación y los artículos citados arriba de la Constitución de 1978 ?

Según lo expuesto en las páginas anteriores, como síntesis del pensamiento de Adolfo Posada, la fórmula «legítimo heredero de la dinastía histórica», que se recoge en el art. 57.1, era ya imposible traer a colación a consecuencia de la ruptura del pacto constitucional de Alfonso XIII, salvo como una figura de derecho privado: como heredero de una estirpe, cuya legitimidad constitucional había perdido.

En este tema me he situado como historiadora del Derecho que intenta adentrarse en el pensamiento de Adolfo Posada en uno de sus temas nucleares de análisis, que lo plantea en varios de sus trabajos y que sintetiza en su Tratado de Derecho político: el tema de la Soberanía y su titularidad: bien en la nación, bien en el rey y que él analiza en el constitucionalismo español, uniendo ciencia jurídica con acontecimientos históricos, como no puede ser de otra manera al abordar un análisis de este tipo por el primer constitucionalista español, que además, tuvo la vivencia directa de los efectos de las dos Constituciones que aquí interesa abordar: la de 1876 y 1931 y posteriormente la solución de la Constitución de 1978.

Siguiendo estas premisas, tengo que concluir que según el desarrollo realizado por Adolfo Posada de dicho proceso, habría que poner en conexión el

${ }^{35}$ Este art. 57.1 prevé la sucesión «normal», mientras que los 57.2 a 57.4 los extraordinarios:

«57.2: El Príncipe heredero, desde su nacimiento o desde que se produzca el hecho que origine el llamamiento, tendrá la dignidad de Príncipe de Asturias y los demás títulos vinculados tradicionalmente al sucesor de la Corona de España.

57. 3: Extinguidas todas las líneas llamadas en Derecho, las Cortes Generales proveerán a la sucesión en la Corona en la forma que más convenga a los intereses de España.

57.4: Aquellas personas que teniendo derecho a la sucesión en el trono contrajeren matrimonio contra la expresa prohibición del Rey y de las Cortes Generales, quedarán excluidas en la sucesión a la Corona por sí y sus descendientes»».

Las abdicaciones y renuncias y cualquier duda de hecho o de derecho que ocurra en el orden de sucesión a la Corona se resolverán por una ley orgánica. 
decreto de 12 de noviembre de 1923, que había roto totalmente el régimen de la Constitución de 1876, de modo especial en su exposición de principios recogida en el Preámbulo, que basaba la soberanía en el pacto entre las Cortes y el rey ${ }^{36}$.

Ahora, en la Constitución de 1978, el art. 57 está prácticamente camuflado en el texto constitucional y hay una suerte de contradicción entre el Preámbulo, donde no se recoge ninguna declaración de principios sobre el régimen que se adopta, el art. 1.2, donde recoge claramente la titularidad de la soberanía en el pueblo español y el art. 57, que alega a unos derechos históricos rotos desde el punto de vista de la técnica jurídica constitucional.

Dentro de la técnica jurídica constitucional, no hubiera habido ningún problema en haber de nuevo retomado la titularidad de la soberanía en el rey y las Cortes o las Cortes y el rey, puesto que se trataba de un nuevo texto constitucional, después de una dictadura y un proceso constituyente; eludir los derechos históricos, como en otros artículos, hubiera sido, quizás, más coherente.

Realmente, yo creo que se puede sostener que la Constitución de 1978 ha procurado ocultar su doctrinarismo en lugar de proclamarlo, como hizo la de Cánovas.

TITLE: Chronic and attitude of a constitutionalist. The thesis of Adolfo Posada on the ownership of sovereignty

RESUMEN: las observaciones recogidas en estas páginas pretenden señalar cual fue la preocupación principal que puede deducirse de los escri-

36 «El decreto de 12 de noviembre de 1923 destruyó totalmente el régimen de la Constitución. El incumplimiento del art. 32 [de la Constitución de Cánovas] que como el eje del mecanismo constitucional, y que exige, como condición esencial de su funcionamiento, la continuidad de la acción de «las Cortes con el Rey», era la negación o anulación del Preámbulo de la Constitución de 1876, expresión formal del «pacto constitucional». En efecto, se formula el pacto constitucional, en dicho Preámbulo, cuando el Rey -Don Alfonso XIIdice que «en unión y de acuerdo con las Cortes y el Reino actualmente reunidas, hemos venido a decretar y sancionar la siguiente Constitución. El cumplimiento del «pacto constitucional» exigía inexcusablemente la colaboración según las normas de la Constitución, de la Corona y de las Cortes. Ahora bien: cómo se determinaba y definía por la Constitución misma, la condición de qué dependía un normal - constitucional- cumplimiento del pacto, consistía en la presencia constante como instituciones del Poder, de cada cual según su competencia, de la Corona y de las Cortes. Lo dice de manera bien precisa el art. 32, que se infringe o se suprime con ademán de dictadura en el decreto de 12 de noviembre de 1923. Desde ese momento ya no podía hablarse de pacto constitucional: la Monarquía del Manifiesto de Sandhurst -hereditaria y constitucional- dejaba de ser constitucional, renaciendo entonces la soberanía de la Nación», PosADA, A., Tratado de Derecho político, II, p. 303. El Manifesto de Sandhurst de 1 de Diciembre de 1874, puede consultarse en: $<$ http://www.xtec.cat/ jrovira6/restau11/sandurst.htm> [Consulta: 2-1-2016]. 
tos de Adolfo Posada acerca de la forma politica que la historia constitucional había impuesto a la España de su tiempo. Intentaré también mostrar como, pese a su evidente fracaso real, el peso de su lógica interna fue tal, que los constitucionalistas de 1978 optaron por sortear su tesis, casi al modo en que se «ocultan» algunos de los intérpretes del Derecho musulmán.

Palabras ClaVE: Segunda república española, Adolfo Posada, soberanía.

ABSTRACT: the observations in these pages are intended to point out what was the main concern can be gleaned from the writings of Adolfo Posada about politics so that constitutional history had imposed the Spain of his time. I will try also to show how, despite its obvious real failure, the weight of its internal logic was such that the Constitutionalists of 1978 chose to circumvent his thesis, about the way they "hide» some of the interpreters of Muslim law.

KEY WORDS: Second Spanish Republic, Adolfo Posada, sovereignty.

RECIBIDO: 07.06.2016

ACEPTADO: 22.06.2016 